\title{
A study to assess the awareness and knowledge about the maternal nutrition and complications encountered by the antenatal mothers in the rural population
}

\author{
Sindhu S. ${ }^{1 *}$, Vidhya D. ${ }^{1}$, Sivankumar K. ${ }^{1}$, Karthiga M. A. ${ }^{2}$
}

\author{
${ }^{1}$ Department of Obstetrics and Gynecology, Melmaruvathur Adhiparashakthi Institute of Medical Science, \\ Melmaruvathur, Tamil Nadu, India \\ ${ }^{2}$ Department of Obstetrics and Gynecology, JSS Medical College, Mysore. Karnataka, India
}

Received: 03 April 2017

Accepted: 02 May 2017

\section{*Correspondence:}

Dr. Sindhu S.,

E-mail: sindhusangaran@gmail.com

Copyright: (c) the author(s), publisher and licensee Medip Academy. This is an open-access article distributed under the terms of the Creative Commons Attribution Non-Commercial License, which permits unrestricted non-commercial use, distribution, and reproduction in any medium, provided the original work is properly cited.

\begin{abstract}
Background: Nutrition plays a vital role in life. Good nutrition is an important part of leading a healthy lifestyle. A healthy pregnancy diet will promote your baby's growth and development. The purpose of this study was to highlight the knowledge, attitude and practices of pregnant women regarding the healthy diet, psychological support, regular visits, danger signs and complications during pregnancy among mothers who visit our hospital along with different socio demographic factors.

Methods: This study was conducted on 350 antenatal women from January 2016 to February 2017 at Tamil Nadu, India. A 24 point- 15 minutes' questionnaire was designed about the knowledge, attitude and practice about the nutrition, danger signs and complications in pregnancy.

Results: Around $98 \%$ of women were very clear that nutrition is necessary in pregnancy and $53 \%$ of them told that the quantity of food intake should be increased. Major source of knowledge about the nutrition was obtained from the family members $(81 \%)$. The common danger sign was abdominal pain $(61 \%)$ followed by bleeding per vaginum $(22 \%)$. About $77 \%$ of mothers had an idea that minimum of 6-10 visit should be there in their antenatal period.

Conclusions: This study emphasizes that health professionals should concentrate more in the nutritional values and the antenatal classes should be taken regarding the role of adequate nutrition, constituents and sources of balanced diet and the consequences of over and under nutrition.
\end{abstract}

Keywords: Antenatal, Danger sign, Nutrition

\section{INTRODUCTION}

Pregnancy is a precious period, where the mother prepares herself physically and psychologically for birth and parenthood. ${ }^{1}$ From social and medical point of view, pregnancy is a very important event. Among the health care delivery systems, antenatal care is considered as an important service. However, some problems or complications which are life threatening both for the mother and fetus may be anticipated during pregnancy. ${ }^{2}$ In 2015, approximately 303000 women and adolescent girls died as a result of pregnancy or childbirth related complications. But $99 \%$ of the maternal death can be preventable. $^{3}$ In India the maternal mortality was estimated to be 556 per 1,00,000 live birth in 1990 but it gradually decreased to 174 per $1,00,000$ live birth in 2015. With this statistical data, it is found that India failed to achieve the Millennium developmental goals. ${ }^{4}$ The most important critical strategy to reduce the 
maternal mortality is proper antenatal care, because it facilitates the early identification and mitigation of risk factors in pregnancy. Essential services are provided when there is timely and frequent antenatal visit. ${ }^{5}$

Now the WHO has increased the number of antenatal visits to eight from four to reduce the antenatal complications. ${ }^{6}$ The major goal of antenatal care are health promotion, disease prevention, dietary advice, early detection and treatment of existing disease and complications, awareness about the danger signs and birth preparedness. ${ }^{7}$ The purpose of this study was to highlight the knowledge, attitude and practices of pregnant women regarding the healthy diet, psychological support, regular visits, danger signs and complications during pregnancy among mothers who visit our hospital.

\section{METHODS}

This is a cross-sectional institution based study conducted on 350 antenatal women from August 2016 to February 2017 at Melmaruvathur Adhiparashakthi Institute of Medical Sciences and Research Institute, Melmaruvathur, Tamil Nadu, India. A 24 point-15 minutes' questionnaire was designed in local language to collect the information about the knowledge, attitude and practice about the food habits, psychological support, regular visits, danger signs and complications in pregnancy. This questionnaire was used to collect the information from the antenatal mothers who attend our antenatal clinic situated in the rural area.

These pregnant women were very well explained about the study and they were asked to fill the questionnaire when they are waiting in the antenatal clinic. The illiterate patients were guided by our junior residents who read the questionnaire without giving any hint or leading answers.

\section{RESULTS}

Table 1: Questionnaire include the following topics.

\section{Topics:}

Demographic information about age, SES, parity, education status and inter pregnancy interval

Need of nutrition in pregnancy

Knowledge about the quantity of food intake

Knowledge about harmful effects of over or under nutrition during pregnancy

Knowledge about source of carbohydrate, proteins, iron, vitamins and minerals.

Importance of nutrition in fetus growth

Knowledge about the weight gain in pregnancy

Significance of acquiring knowledge about nutrition in pregnancy

Source of information

Danger signs in pregnancy

Knowledge about the visits
About three hundred and fifty antenatal mothers were participated in the present study. Out of them $88 \%$ of women were between 21-30 yrs of age and $66 \%$ of women had secondary and higher secondary level of education. Majority of the women were multi gravida accounting for $73 \%$ followed by primigravida (22\%) and grand multi (5\%). According to Modified Kuppuswami classification $46 \%$ of antenatal mothers belong to class 4 followed by $43 \%$ in class 5 (Table 2).

Table 2: Socio-demographic variables of the study population.

\begin{tabular}{|l|l|}
\hline Age (years) & Percent \\
\hline$<20 y r s$ & 5 \\
\hline $21-30 y r s$ & 88 \\
\hline$>30 y r s$ & 7 \\
\hline Education status & \\
\hline Degree & 26 \\
\hline Secondary and higher secondary & 66 \\
\hline Primary & 5 \\
\hline Nil & 3 \\
\hline Parity & \\
\hline G1 & 73 \\
\hline G2 & 22 \\
\hline$>$ g3 & 5 \\
\hline Interpregnancy interval (in years) & \\
\hline G1 & 22 \\
\hline <1yr & 3 \\
\hline $1-2 y r s$ & 28 \\
\hline 2-3yrs & 31 \\
\hline 3-4yrs & 10 \\
\hline 4-5yrs & 3 \\
\hline$>6$ and above & 3 \\
\hline Ses (modified kuppuswami classification) & \\
\hline Class 2 & 2 \\
\hline Class 3 & 9 \\
\hline Class 4 & 46 \\
\hline Class 5 & 43 \\
\hline
\end{tabular}

Around $98 \%$ of women were very clear that nutrition is necessary in pregnancy and $53 \%$ of them told that the quantity of food intake should be increased.

Only $17 \%$ was aware about the risk of over and under nutrition. About $56 \%$ of women were conscious about the dietary supplements in the food. Adverse effects due to weight gain were known to $58 \%$ of antenatal mothers. Forty-nine percentages of mothers were aware about the importance of nutrition for fetus.

Major source of knowledge about the nutrition was obtained from the family members $(81 \%)$ followed by doctors (32\%) and nurses (10\%) (Figure1).

The common danger sign which were commonly known to the antenatal mothers was abdominal pain (61\%) followed by bleeding per vaginum $(221 \%)$, pedal edema $(15 \%)$, fever $(12 \%)$ and decreased fetal movements 
(10\%) (Figure 2). About $77 \%$ of mothers had an idea that minimum of $6-10$ visit should be there in their antenatal period (Table 3).

Table 3: Questionnaire results.

\begin{tabular}{|c|c|}
\hline \multicolumn{2}{|c|}{ Need of nutrition in pregnancy } \\
\hline Yes & $98 \%$ \\
\hline No & $2 \%$ \\
\hline \multicolumn{2}{|c|}{ Knowledge about the quantity of food intake } \\
\hline Same quantity & $34 \%$ \\
\hline Decreased quantity & $13 \%$ \\
\hline Increased quantity & $53 \%$ \\
\hline \multicolumn{2}{|c|}{$\begin{array}{l}\text { Knowledge about harmful effects of over and } \\
\text { under nutrition }\end{array}$} \\
\hline Yes & $17 \%$ \\
\hline No & $83 \%$ \\
\hline \multicolumn{2}{|c|}{$\begin{array}{l}\text { Knowledge about source of carbohydrate, proteins, } \\
\text { iron, vitamins and minerals }\end{array}$} \\
\hline Yes & $56 \%$ \\
\hline No & $44 \%$ \\
\hline \multicolumn{2}{|c|}{ Importance of nutrition in fetus growth } \\
\hline Yes & $49 \%$ \\
\hline No & $51 \%$ \\
\hline \multicolumn{2}{|c|}{ Knowledge about the weight gain in pregnancy } \\
\hline Yes & $58 \%$ \\
\hline No & $42 \%$ \\
\hline \multicolumn{2}{|c|}{$\begin{array}{l}\text { Significance of acquiring knowledge about } \\
\text { nutrition in pregnancy }\end{array}$} \\
\hline Yes & $61 \%$ \\
\hline No & $39 \%$ \\
\hline \multicolumn{2}{|l|}{ Source of information } \\
\hline Doctor & $32 \%$ \\
\hline Husband & $15 \%$ \\
\hline Mother & $56 \%$ \\
\hline Mother in law & $10 \%$ \\
\hline Nurse & $10 \%$ \\
\hline Others & $2 \%$ \\
\hline \multicolumn{2}{|l|}{ Danger signs in pregnancy } \\
\hline \multicolumn{2}{|l|}{ Abdominal pain } \\
\hline Leaking per vagina & $61 \%$ \\
\hline Decreased fetal movements & $9 \%$ \\
\hline Bleeding per vagina & $10 \%$ \\
\hline Pedal edema & $22 \%$ \\
\hline Giddiness & $15 \%$ \\
\hline Vomiting & $4 \%$ \\
\hline Increased blood pressure & $6 \%$ \\
\hline Increased blood sugars & $1 \%$ \\
\hline Headache & $2 \%$ \\
\hline Fever & $12 \%$ \\
\hline Others & $3 \%$ \\
\hline No idea & $23 \%$ \\
\hline \multicolumn{2}{|l|}{ Knowledge about the visits } \\
\hline$\leq 5$ visits & $9 \%$ \\
\hline $6-10$ visits & $77 \%$ \\
\hline $11-15$ visits & $6 \%$ \\
\hline$>15$ visits & $6 \%$ \\
\hline No idea & $2 \%$ \\
\hline
\end{tabular}

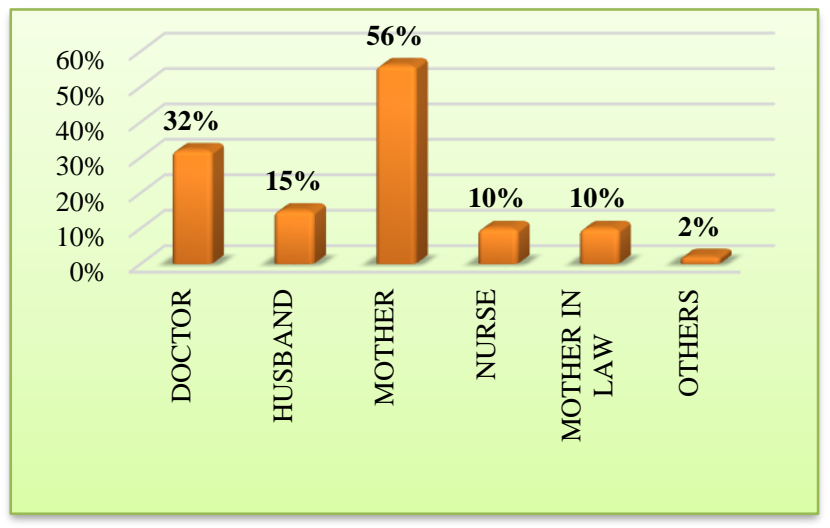

Figure 1: Source of information.

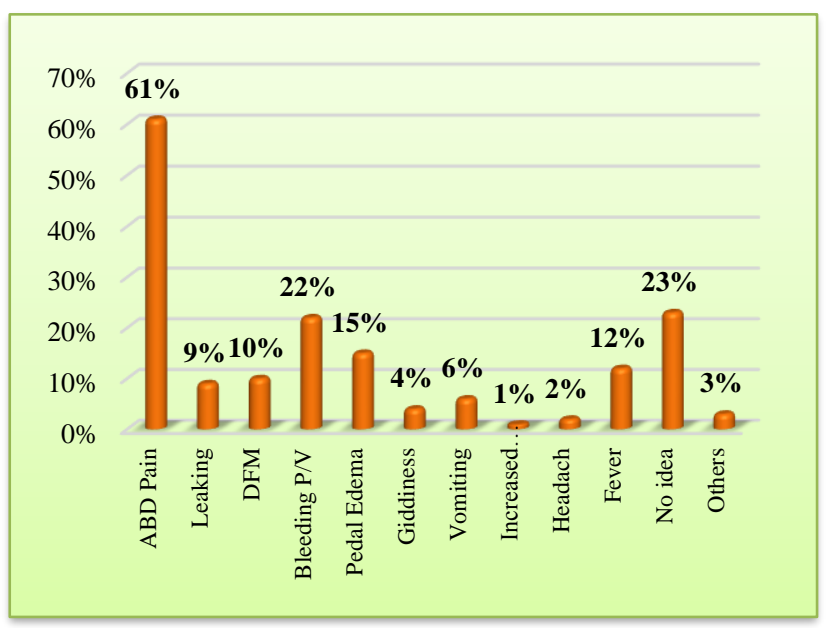

Figure 2: Danger signs.

\section{DISCUSSION}

Sufficient nutrition is essential to live a life. Pregnancy is a precious period for all women. Need of nutrition is more in pregnancy. Inspite of constant plea in literature there is no adequate information regarding insufficient or too much weight gain during pregnancy. Not many studies were found regarding the need for nutrition and the knowledge about the same in pregnancy. The current study was done to audit the present knowledge of nutrition in pregnancy among gravid mothers. In the present study $98 \%$ of pregnant women were aware that nutrition is important in pregnancy. According to Mulhausler, Adam and McMillan maternal nutritional status at the time of conception influences more on the maternal and fetal mortality and morbidity. ${ }^{8}$ More than half $(53 \%)$ of the gravid mothers were conscious that the quantity of food intake should be increased during pregnancy. Contrary to this only $17 \%$ were aware about the harmful effects of over and under nutrition in pregnancy. This may be due to low maternal education level which was similar to other studies.,10 This study also revealed that $44 \%$ of mothers didn't have enough knowledge regarding balanced diet, source of macro and micronutrients. This can be attributed to the fact that most 
of them were housewives hence they were not assessed to the source of information and they didn't attend the antenatal clinic in an appropriate number. This was similar to the other study. ${ }^{9,10}$ If the mother recognizes the importance of good nutrition then she will plan her pregnancy properly which will reflect on her pregnancy. ${ }^{11}$

More than half (49\%) of the mothers lack the knowledge about the importance of nutrition in fetus growth which influence on infant mortality and morbidity. The present study was conducted in the rural area where most of the gravid mothers belongs to low socioeconomic status with low education level. This was very much alike with the other two studies. ${ }^{9,10}$ Out of the total participants $77 \%$ of them had an idea about the danger signs in pregnancy. Among them abdominal pain was told by $62 \%$ followed by bleeding per vaginum $(22 \%)$, pedal edema $(15 \%)$, fever $(12 \%)$ and decreased fetal movements $(10 \%)$. This was much higher when compared to the study done in 2011 but similar to the study done in $2014 .{ }^{12,13}$ The reason may be due to different cultural and geographical variation. Along with that the health education provided by the auxiliary nurse midwifery (ANM) in their field visits also play a vital role in this. WHO has now increased the number of antenatal visits to prevent the complications during pregnancy. ${ }^{4}$ In our study $77 \%$ of women were aware about the increased visits during pregnancy. This may be due to ANM who taught them during their field visits. In most of the pregnant women the source of information was their family members ( $81 \%)$ and only very few acquired information from the doctor and ANM. This was similar to the study conducted by Gupta et al. ${ }^{10}$

\section{CONCLUSION}

One of the main aims of millennium developmental goal of India was to improve the maternal health. In spite of implementing many schemes and goals for the betterment of nutritional value in the antenatal mother, the destination is still a dream in India. The major sources of nutrition for antenatal mothers are their family members when compared to doctors and the health workers. In addition to that various myths have been followed among the pregnant mothers in the rural area. Health professionals should concentrate more in the nutritional values and the antenatal classes should be taken regarding the role of adequate nutrition, its constituents, its sources and the consequences of over and under nutrition especially in the illiterate and under educated women. The government should employ more number of health professionals to educate the women to have a healthy outcome of the mother and their children.

\section{Funding: No funding sources} Conflict of interest: None declared

Ethical approval: The study was approved by the Institutional Ethics Committee

\section{REFERENCES}

1. Lowdermilk. Nursing care of the family during pregnancy. In: Deitra L, Shannon E, Mary C,eds. Maternity nursing. US, Mosby; 2013:190-237.

2. Fraser M, Cooper A. Myles Textbook for Midwives. ! $4^{\text {th }}$ ed., Churchill Livingston, Edinburgh; 2003:40-2.

3. Alkema L, Chou D, Hogan D, Zhang S, Moller A-B, Gemmill A et al; United Nations Maternal Mortality Estimation Inter- Agency Group collaborators and technical advisory group. Global, regional and national levels and trends in maternal mortality between 1990 and 2015, with scenario-based projections to 2030: a systemic analysis by the UN Maternal Mortality Estimation Inter Agency Group. Lancet. 2016;387(10017):462-74.

4. The World Bank. WHO, UNICEF, UNFPA, World Bank Group and the United Nation population division trends in maternal mortality: 1990 to 2015 . Geneva, WHO; 2015. Available from: URL: http://data.worldbank.org/indicator/SH.STA.MMRT.

5. Bhutta ZA, Chopra M, Axelson H, Berman P, Boerma T, Bryce J, et al. Countdown to 2015-decade report (2000-10): taking stock of maternal, newborn, and child survival. Lancet. 2010;375(9730):2032-44.

6. WHO recommendations on antenatal care for a positive pregnancy experience. Available from: URL: http://www.who.int/reproductivehealth/publications/mat ernal_perinatal_health/anc-positive-pregnancyexperience/en/.

7. Federal Democratic Republic of Ethiopia, Ministry of Health; management protocol on selected obstetrics topics, January; 2010.

8. Mulhausler B, Adam C, McMillan C, Maternal nutrition and the programming of obesity. Organogenensis. 2008;4(3):144-52.

9. Latifa MF, Manal HA, Nihal SS. Nutritional awareness of women during pregnancy. $\mathrm{J}$ American Sci. 2012;8(7):494-502.

10. Gupta R, Agarwal S, Singh N, Jain R, Katiyar A, Siddiqui A. A study to assess knowledge and attitude of antenatal women about maternal nutrition attending a tertiary care centre. Int $\mathrm{J}$ Reprod Contracep Obstet Gynecol. 2016;5:1549-52.

11. Wu G, Bazer F, Cudd, T. Maternal Nutrition and Fetal Development. J Nutrition. 2004;34: 2169-72.

12. Kabakyenga. Knowledge of obstetric danger signs and birth preparedness practices among women in rural Uganda Reproductive Health. 2011;8(33). Available at: http://www.reproductive-health-journal.com/content /8/1/3.

13. Gebrehiwot H, Bahta S, Haile N. Awareness of Danger Signs of Pregnancy and its Associated Factors among Pregnant Women who Visit ANC in Mekelle Public Hospitals. Am J Adv Drug Deliv. 2014;2(2):164-73.

Cite this article as: Sindhu S, Vidhya D, Sivankumar $\mathrm{K}$, Karthiga MA. A study to assess the awareness and knowledge about the maternal nutrition and complications encountered by the antenatal mothers in the rural population. Int J Reprod Contracept Obstet Gynecol 2017;6:2532-5. 